\title{
HISTORIA DE LA EDUCACION EN COLOMBIA
}

\section{Planteamiento del problema}

Es sorprendente la bibliografía hoy existente sobre el sector educativo; ya no aparece como un apéndice de trabajos especializados sino como un grueso volumen. Sin embargo, el hecho de que exista en tal forma no implica de por sí que se posea una comprensión sistemática y global del sector. La gran mayoría de los trabajos son descriptivos y sectoriales cuando no filosóficos. El estudio realizado y acumulado sobre el sistema educativo colombiano parece hoy agotar la dimensión descriptiva exigiendo análisis de mayor profundidad explicativa.

La exigencia de esta investigación no se justifica sólo en términos del material acumulado que posibilita una rigurosa comprensión de su estructura, de su lógica y de su funcionamiento, sino que es demandable fundamentalmente por la urgencia de afianzar la planeación educativa sobre soportes más sólidos y menos inmediatos, vale decir, más históricos.

Las complejas relaciones de las políticas educativas con la legislación escolar y de ellas con la realidad empírica del sistema y su orientación real, sólo pueden ser analizadas en sus coherencias e incoherencias, en sus desfases y contradicciones, refiriéndonos a sus múltiples vínculos con el contexto social, económico y político. Son estas determinaciones, las que permiten una explicación sistemática de aquéllas.

La política educativa está orientada a influir sobre el contexto que la determina, y por esta razón, esclarecer sus formas de articulación, es una prioridad para que la eficacia de esa influencia sea algo más que un buen propósito.

Desde luego, el estudio científico de la historia no produce fórmulas mágicas, pero puede aproximar un cuadro que ilumina la forma cómo un determinado proceso se da; puede prever con alguna certeza que dentro de una conjunción de factores que se han dado como invariables, y sólo si el contexto no se modifica, los resultados serán similares, pero de ninguna manera anticipar con precisión cómo se darán. Los resortes que condicionan la modificación, no están en manos del estudioso, sino, y restringidamente en manos del político.

Sin duda también existen razones menos prácticas que avalan el enfoque histórico. Un conocimiento tan solo superficial de las relaciones entre el sistema educativo y su contexto social, sería una contribución importante a la historia de nuestra cultura, la lógica de nuestra interpretación del mundo.

\section{Objetivo y propósitos del proyecto}

Por definición la historia no es una plena identidad cronológica, sino un proceso donde es posible leer modos peculiares de expansión y desarrollo de sus leyes; característica que permite periodizar la historia en función de esas formas específicas de articulación de los elementos que constituyen el proceso.

Nuestro propósito es comprender el sistema educativo determinado por la estructura económica, política y social, en su movimiento motriz, explicativa que no puede ser captada como instante sino como proceso, es decir, como historia. 
En concordancia con nuestro objetivo, hemos definido el período del Frente Nacional como el lapso de mayor significación para el análisis del contexto que determina al sistema educativo. Las grandes tendencias que allí se incuban, son hoy plenamente vigentes y nuestra inmediata contemporaneidad hace parte integral de este trozo histórico. Los elementos económicos, políticos y sociales que dan a nuestro presente una personalidad bien alinderada, comienzan su gestación hacia los años 30 y alcanzan un nítido perfil hacia los años 50. El Frente Nacional es un período de sedimentación y maduro desenvolvimiento de las tendencias.

De otro lado, es oportuno recordar que a partir del Frente Nacional, el estado promueve una política educativa de mayor envergadura, orientada más coherentemente a las realidades sociales tanto de corto como de largo plazo. La planeación educativa como proyecto de racionalización del sector comienza a funcionar paralelamente al acuerdo político bipartidista.

No obstante, el Frente Nacional no puede ser visto como una simple forma de nuestra historia constitucional. Hunde sus raíces no sólo en el terreno económico y social sino fundamentalmente en la historia de estas dimensiones. Por ello nuestra investigación deberá referirse necesariamente a los antecedentes históricos inmediatos: La violencia y más que a esta expresión, a sus verdaderas realidades constitutivas.

Podríamos postular como guía analítica a la violencia, como la gran partera del Frente Nacional, la condición de que ella se entienda como una prolongación y un instrumento de cambio en la estructura agraria del país y de una diferente función que esta estructura asuma en relación con el aparato productivo global. Desde luego, no hablamos de violencia de manera restringida al mundo rural y a su conceptualización legal, sino a la violencia como expresión e instrumento del descoyuntamiento de la vieja legalidad.

La fractura del orden legal que implica la violencia puede ser explicada, apelando a los grandes cambios económicos que venían gestándose e impulsándose a partir de los años 30 .

Consideramos que la educación es en general un complejo institucional determinado y determinante de tres grandes instancias: La estructura económica, el estado y los partidos políticos, las luchas y contradicciones sociales. Nos referimos a la educación como un fenómeno organizado, intervenido y enmarcado por el estado y no, por tanto, como proceso de ideologización espontáneo.

Claro es que el Estado como aparato que condensa los intereses colectivos, y, por tanto, reproductivos de los sectores dominantes, somete su orientación primordial a ellos. De esta manera la educación, aunque fundamentalmente está orientada a promover la representación dominante, debe también dar cabida a modalidades regionales y en veces disímiles de esta representación. Que esto suceda, depende naturalmente del grado de conflicto social alcanzado en cada momento, aunque debe subrayarse el hecho de que en este dominio y a pesar de los antagonismos objetivos pueden crearse divergencias, pero nunca, espontáneamente antagonismos en la representación.

Luego, la educación es una base que sustenta la dinámica estatal, no solo porque la promueve, la organiza y la interviene, sino en tanto es una mediación por medio de la cual la población la alcanza. Este papel permite al estado la legitimidad social y a los partidos que la administran una importante base de clientelismo político. Comúnmente en los análisis de la educación este factor es olvidado o silenciado. Nosotros lo creemos de vital importancia como una vía al análisis del estado, y como un instrumento metodológico de 
primer grado para la explicación de algunas características del sistema educativo y de su historia.

En consecuencia, el sistema educativo obedece a una doble determinación: Las exigencias propias de la estructura económica y las demandas reproductivas del contexto representativo-ideológico. Pero, hay que entenderle muy claro; tanto una como otra función son cumplidas por mediación del estado. Por esta razón la educación se convierte también en un centro de luchas sociales, de reivindicaciones y de antagonismos, que buscan imprimir peculiares tintes a su dinámica.

Explicar el tejido de esta lógica de mutuas implicaciones, desde un punto de vista histórico, es el propósito explícito del trabajo que nos proponemos adelantar.

\section{Metodología}

Partiendo de nuestro marco teórico, el sistema educativo metodológicamente debe ser explicado en función de las variables división técnica y social del trabajo, modalidades de la acumulación y concentración de capital, composición orgánica y desarrollo de las fuerzas productivas, formas de reproducción del sistema productivo. Creemos que es más eficaz hacerlo a partir de una caracterización-descripción de la educación. En otras palabras procederemos primero a forjar los perfiles del sistema educativo para buscar luego su comprensión contextual:

A. Descripción cronológica de la legislación de las políticas educativas y de las presiones por parte de los sectores sociales.

B. Descripción del sistema educativo en su conformación empírica 1938-1974. Financiamiento, estructura académica (desarrollo de los niveles y ciclos) profesorado, currículum, infraestructura escolar, etc.

C. Análisis de los desfases y relaciones entre "presiones", políticas, legislación y estructura empírica.

D. Determinación de tendencias y modelos significativos para buscar su explicación en relación al contexto.

\section{Fuentes}

A. Utilizaremos básicamente fuentes secundarias: Estudios realizados sobre el sector, estadísticas sistematizadas, memorias de ministros, mensajes presidenciales, informes de comisiones técnicas, debates parlamentarios, legislación escolar, ensayos y editoriales de prensa, etc.

B. También nos proponemos realizar entrevistas a individuos que por su función política o por su conocimiento directo de la problemática, pueden aportar elementos significativos para la explicación que buscamos.

C.Análisis de los desfases y relaciones entre "presiones", políticas, legislación y estructura empírica.

D.Determinación de tendencias y modelos significativos para buscar su explicación en relación al contexto. 